Int. J. Dev. Biol. 48: 23-29 (2004)

Original Article

\title{
Quantitative gene expression profiling reveals a fetal hepatic phenotype of murine ES-derived hepatocytes
}

\author{
ANDREA JOCHHEIM, TINA HILLEMANN, GABRIELA KANIA ${ }^{1}$, JENNIFER SCHARF, MASOUMEH ATTARAN, \\ MICHAEL P. MANNS, ANNA M. WOBUS ${ }^{1}$ and MICHAEL OTT* \\ Hannover Medical School, Center of Internal Medicine, Department of Gastroenterology, Hepatology and Endocrinology, Hannover and ${ }^{1}$ In \\ vitro Differentiation Group, Institute of Plant Genetics, and Crop Plant Research, Gatersleben, Germany
}

\begin{abstract}
To use embryonic stem (ES) cells in future therapeutical applications, differentiated hepatic phenotypes with specific liver functions would be necessary. We analyzed albumin (ALB), $\alpha$-fetoprotein (AFP) and hepatic transcription factor (TF) gene expression in tissues derived from embryonic, fetal and adult liver, and compared the gene expression profiles with those from mouse ES cells after hepatic differentiation and from cultured adult hepatocytes. The mRNA expression of hepatocyte nuclear factor (HNF)-1 $\alpha, \beta,-3 \alpha, \beta,-4 \alpha,-6, C C A A T / e n h a n c e r$ binding protein (C/EBP) $\alpha, \beta, A L B$ and AFP relative to glyceralaldehyde-3-phosphate dehydrogenase (GAPDH) were studied by "real time" RT-PCR. ALB and AFP-expression was also determined by in situ hybridization (tissue) and immunofluorescence (ES-derived cells after hepatic differentiation, ES-HPC). Peak levels for HNF-1 $\alpha,-3 \alpha,-4 \alpha$ and -6 were detected in early liver development at d9.5 and d11.5. C/EBP $\alpha$ and $\beta$ were most abundantly expressed in adult liver. ALB mRNA increased steadily from d10.5 on and was maximally present in adult liver. AFP was present at d9.5, peaked at d15.5 and dramatically declined in mature liver tissue. Based on immunofluorescence, ALB and AFP were expressed in 20\% of ES-HPC. While expression of HNF-3, 4 and 6 reached levels similar to adult hepatocytes, $A L B$ and $A F P$ expression was several orders of magnitude lower than in adult tissue or cells. Stages of liver organogenesis are characterized by specific expression patterns of developmentally regulated genes. With sophisticated differentiation protocols, hepatic gene expression can be induced in a proportion of ES cells with gene expression patterns similar to early fetal liver.
\end{abstract}

KEY WORDS: embryonic stem cells, gene expression studies, differentiation into hepatic phenotypes

\section{Introduction}

Primary hepatocytes are used extensively in pharmacology and toxicology research for predicting the metabolism of xenobiotics and drug components (Tirona et al., 2003). Also, numerous animal studies and several human applications have suggested a prominent role of hepatocytes in future cell therapy protocols (Gupta, 2002). For preparation of sufficient numbers of human hepatocytes, however, the lack of suitable donor tissues remains an obstacle. Stem cells, which can be propagated and differentiated in culture, are considered as ideal source for functional hepatocytes. Hepatic stem cells have been described in murine and human livers and have been used to generate hepatocytes, but significant numbers necessary for therapeutic application have not been generated (Zhang et al., 2003). An alternative source for primary hepatocytes are embryonic (ES) stem cells which have almost unlimited proliferation capabilities while retaining the potential to differentiate in vitro into various progenitor cells (Chinzei et al., 2002).

The transcriptional events involved in the formation of liverspecific progenitor cells from pluripotent ES cells are poorly understood. Several groups have shown that pluripotent murine ES cells can differentiate into cells with a presumed hepatic phenotype in culture and integrate and function after transplantation into a host liver (Hamazaki et al., 2001; Jones et al., 2002). Although differentiation of hepatic progenitor cells into mature

Abbreviations used in this paper: $\mathrm{ALB}$, albumin, AFP, $\alpha$-fetoprotein; $\mathrm{C} / \mathrm{EBP}$, CCAAT/enhancer binding protein; ES cell, embryonic stem cell; ES-HPC, ES-derived cells after hepatic differentiation; GAPDH, glyceralaldehyde-3phosphate dehydrogenase; $\mathrm{HNF}$, hepatocyte nuclear factor; TF, transcription factor.

\footnotetext{
*Address correspondence to: Dr. Michael Ott. Hannover Medical School, Center of Internal Medicine, Department of Gastroenterology, Hepatology and Endocrinology,30625 Hannover, Germany. Fax: +49-511-906-3534. e-mail: ott-mhh@gmx.de
} 
adult hepatocytes may occur in vivo after transplantation into an appropriate environment, it is currently not known whether differentiation into hepatic cells with complex metabolic functions can be achieved under current cell culture conditions in vitro(Miyashita et al., 2002; Cantz et al., 2003). It is likely that ES cell differentiation in culture is driven by transcriptional events similar to those seen in early organogenesis in vivo. At the molecular level the induction of liver development and its progress is characterized by the expression of TF such as hepatocyte nuclear factors (HNF)-1, HNF-3, HNF-4, HNF-6 and CCAAT/ enhancer binding proteins (C/EBP). These so-called "liver-enriched" TF show a specific expression pattern during organogenesis with a distinct narrow time interval of transcription initiation. Most of these TF, although not themselves liver-specific, are also known to regulate the expression of genes coding for important secretory liver proteins by combinatorial interaction on their promoters in preand postnatal liver (Nacer-Cherif et al., 2003). Among these proteins, $A F P$ is expressed already in early hepatoblasts and later on with increasing levels throughout the fetal development. After birth the AFPgene is selectively silenced (Jones et al., 2001). In contrast, the $A L B$ gene codes for the most abundant serum protein synthesized by the mature liver (Kamiya et al., 1999).

Expression profiles in embryonic liver tissue of the "liver enriched" TF and the developmentally regulated $A \angle B$ and $A F P$ genes may thus represent paradigms for gene regulation in ES cell derived hepatic progenitors cells (ES-HPC) (Lazarevich et al., 2000). In our present study we have analyzed the liver - enriched transcription factors and developmentally regulated genes in mouse liver development. On the basis of these expression data we aimed at understanding the volatile transcriptional events initiated during transition of pluripotent ES cells toward cells with a hepatic phenotype and to provide a new tool to characterize the phenotype of ESHPC.

\section{Results}

\section{ALB and AFP expression in pre- and postnatal murine liver samples}

Quantitative levels of $A L B$ and $A F P$ mRNA expression normalized to the internal reference gene $G A P D H$ at various stages of development are shown in Fig. 1 A,B. AFP expression was found at low levels in $E$ d9.5 liver tissue. The levels in fetal mouse liver steadily increased $\sim 1000$-fold from day 9.5 to 15.5 of gestation and dropped dramatically in adult liver. However, at low levels, AFP was reproducibly detected in multiple adult liver samples by "real time" RT-PCR (Fig. 1A). From E d10.5 on ALBmRNA expression increased continuously and reached maximum in adult liver (Fig. 1B). $A L B$ expression in hepatocytes immediately after isolation, 24 and 48 hours after culture was lower compared to adult liver tissue (Fig. 4).

\section{Liver-enriched TF expression in pre- and postnatal liver samples}

Compared to $A L B$ and $A F P$, expression of transcription factors were several fold lower. $H N F-1 \alpha$ transcripts were first determined in early liver organogenesis at $E \mathrm{~d} 9.5$. No signal was obtained in $E$ d7.5 total embryonic tissue. The mRNA transcription level of $H N F 1 \alpha$ decreased substantially in liver tissue at $E$ d13.5 and showed slightly higher levels again in adult liver tissue. A consid- erable level of $H N F-1 \beta$ mRNA expression was detected only in RNA samples from d 7.5 embryonic tissue and from $E \mathrm{~d} 9.5$ as well as E d11.5 liver tissue. No signal was detected with the standard protocol nor using an increased amount or cDNA synthesized from PolyA(+)-mRNA at later stages. Expression of HNF3 $\alpha$ mRNA reached maximal levels in early embryonic liver at $E \mathrm{~d} 11.5$ and significantly dropped in liver tissue from E d13.5 mice and in adult liver. No signal was detected in $\mathrm{d} 7.5$ total embryonic tissue. Overall, the $H N F-3 \beta$ signal was low and reached similar levels of transcription in whole embryonic tissue at day 7.5 and in liver tissue at E d9.5, d11.5 and E d13.5 of gestation. Pooled RNA samples from $E$ d10.5 liver were also analyzed, which showed levels similar to $\mathrm{E}$ d11.5 and $\mathrm{E}$ d13.5 liver tissue (data not shown). In adult liver the transcription rate was consistently higher compared to early stage tissues. HNF-3 $/$ GAPDH - ratio was $~ 10$ fold lower compared to the average ratio detected for $H N F-3 \alpha$ / GAPDH in our tissue samples. HNF-4 $\alpha$ and HNF-6 mRNA expression were highly expressed at $E \mathrm{~d} 9.5$ and $E \mathrm{~d} 11.5$ in the liver and showed significant lower levels in E d13.5 liver tissue and in adult liver. Both TF mRNAs were not detectable by "real time" RTPCR in tissue from d7.5 whole embryo.

The highest levels of $C / E B P \alpha$ mRNA were detected in adult liver tissue. Only marginal levels were detected in $\mathrm{E} \mathrm{d13.5}$ and $\mathrm{E}$ d16.5 (data not shown) fetal liver. At earlier stages of liver

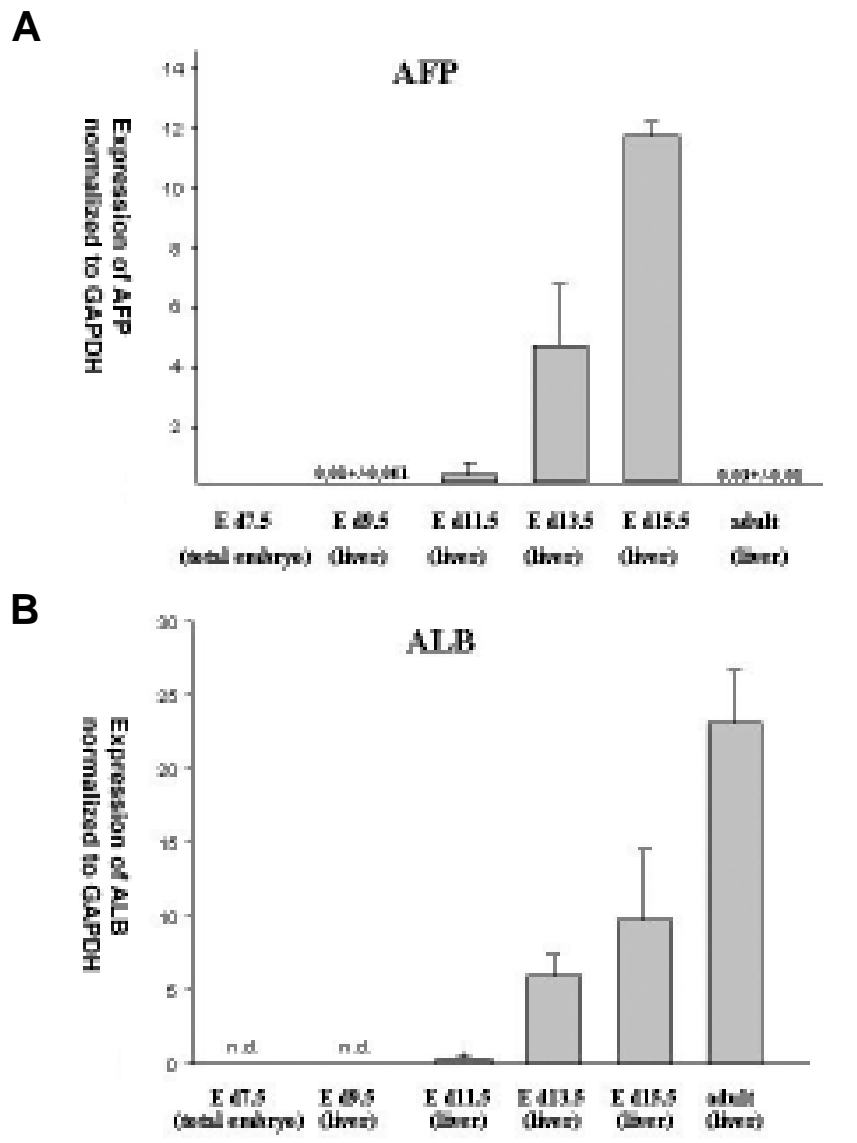

Fig. 1. Patterns of AFP and ALB expression in mice at different stages of liver development. Means and standard deviations of relative AFP (A) and ALB (B) mRNA expression normalized to GAPDH expression. n.d., not detectable 


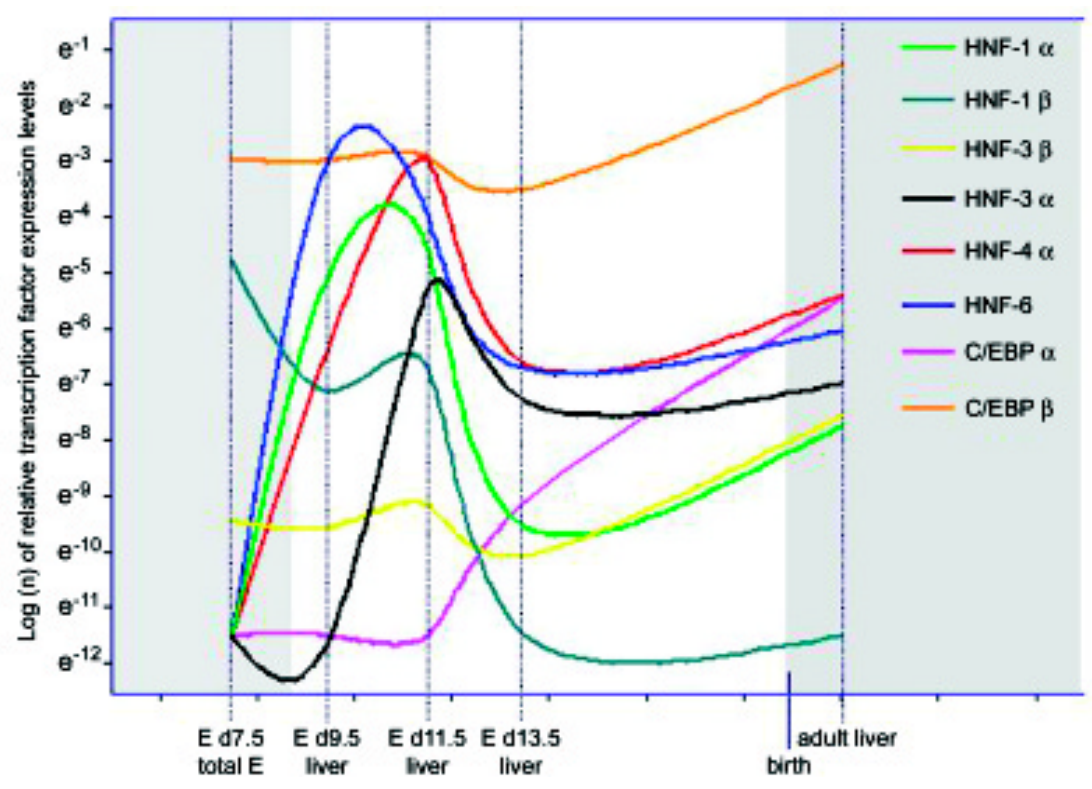

Fig. 2. Expression profiles of several transcription factors at key stages of liver development. Expression patterns for the following TFs are shown in the graph: HNF-1 $\alpha$ and $\beta, \mathrm{HNF}-3 \alpha$ and $\beta, \mathrm{HNF}-4 \alpha, \mathrm{HNF}-6$ and $\mathrm{C} / \mathrm{EBP} \alpha$ and $\beta$. The curves were approximated from the data generated by "real time" RT-PCR.

organogenesis, the transcription factor was not detectable. Among the analyzed liver-enriched TF, the highest number of mRNA copies relative to $G A P D H$ were detected for $C / E B P \beta$ in the liver of adult mice. $C / E B P \beta$ mRNA was detected at all stages of embryonic development, but at a lower level compared to adult liver . Expression profiles of the TF $H N F-1 \alpha \beta, H N F-3 \alpha \beta, H N F-4 \alpha$, $H N F-6$ and $C / E B P \alpha$ and $\beta$ are summarized in Fig. 2. The curves were approximated from the "real time" RT-PCR data that were generated for each TF at all stages of liver development studied.

\section{Liver-enriched TF, ALB and AFP mRNA expres- sion in ES-HPC and primary hepatocytes}

Image analysis of immunofluorescence signals from ES-HPC cells at stage $5+20 \mathrm{~d}$ showed an increase of $A L B(21.7 \pm 5.8 ; \mathrm{n}=6)$ and $A F P(22.0 \pm$ $10.1 ; \mathrm{n}=6)$ abundance in comparison to undifferentiated ES cells (Fig. 3 A-E, for details see legend). The number of ALB-positive cells increased with differentiation time from day $5+10$ to day $5+20$, whereas no significant changes were detected in comparison to day $5+30$. $A F P$ was produced in up to 15,22 and $6 \%$ of the cells at stages $5+10 \mathrm{~d}, 20 \mathrm{~d}$ and $30 \mathrm{~d}$, respectively. Neither $A F P$ nor $A \angle B$ was detected in undifferentiated ES cells (Fig. 3E). As expected from immunofluorescence staining, $A L B$ and $A F P$ mRNA expression was readily measured in ES-HPC cells, but was not detectable in undifferentiated ES cells. The level of expression, however, was lower compared to cultured adult hepatocytes or adult liver tissue. The levels of $A \angle B$ expression corresponded to the levels detected in tissue samples from $\mathrm{E}$ d 10.5 - 11.5 fetal liver. Cultured adult hepatocytes expressed $A \angle B$ at a lower level than primary tissue, but expression levels were still several magnitudes higher than in ES-HPC cells.

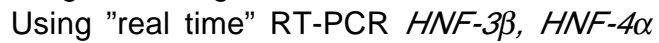
and $H N F-6$ mRNA's were detected in cell samples after 5 days of embryoid body formation and 10,20 or 30 days of hepatic differentiation. HNF-3 $\beta$ levels were also detected in undifferentiated ES cells but increased about three fold after differentiation induction. $C / E B P \alpha$ was not detectable in ES cells, but was readily detectable in cultured adult hepatocytes. $C / E B P \beta$ was not useful for the analysis of differentiation in ES cells, because the TF was highly expressed also in mouse embryonic feeder cells (data not shown). Figure 5 shows the expression rates of the TF HNF3 $\beta$,
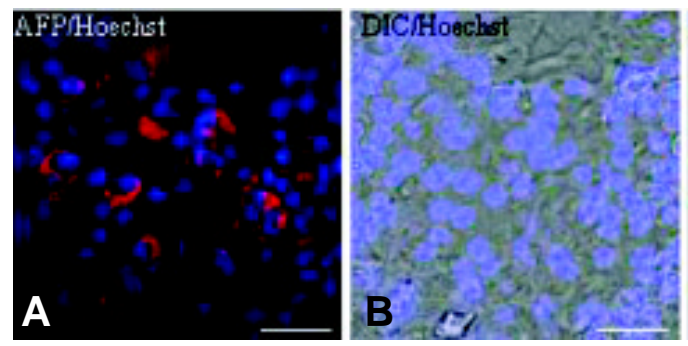

E

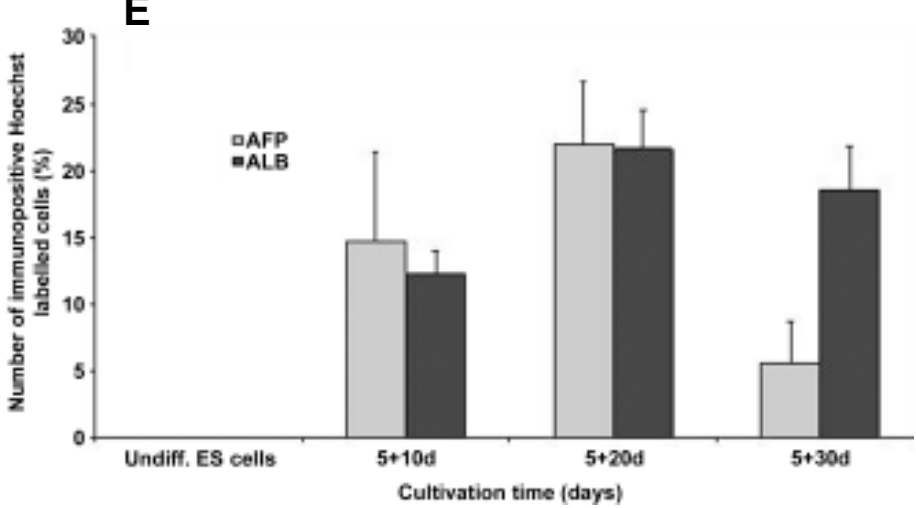

Fig. 3. Immunofluorescence micrographs of AFP and ALB in ES-HPC. Immunofluorescence micrographs of AFP (A) and ALB (C)- labelled cells in ESHPC at stage 5+20d, including Hoechst 33342labelling of nuclei in DIG (B,D) respectively. Bar, 30 $\mu \mathrm{m}$. (E) Semi-quantitative immunofluorescence analysis to estimate the percentage values of Hoechst 33342-labelled ES-HPC cells at stage $5+10 d, 20 d$ and $30 d$ expressing AFP and ALB. Each value of $n=6$ experiments represents mean $\pm S E M$ (standard error of mean). 
A

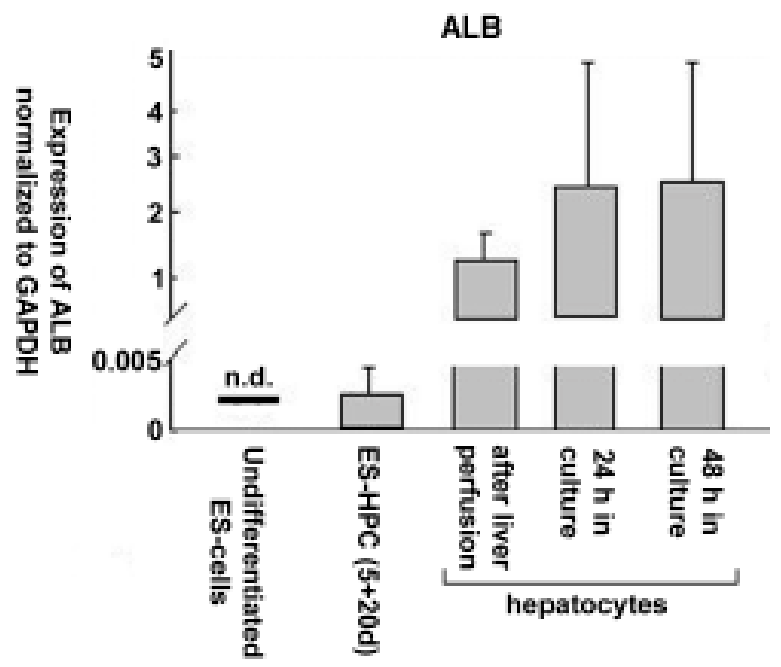

B

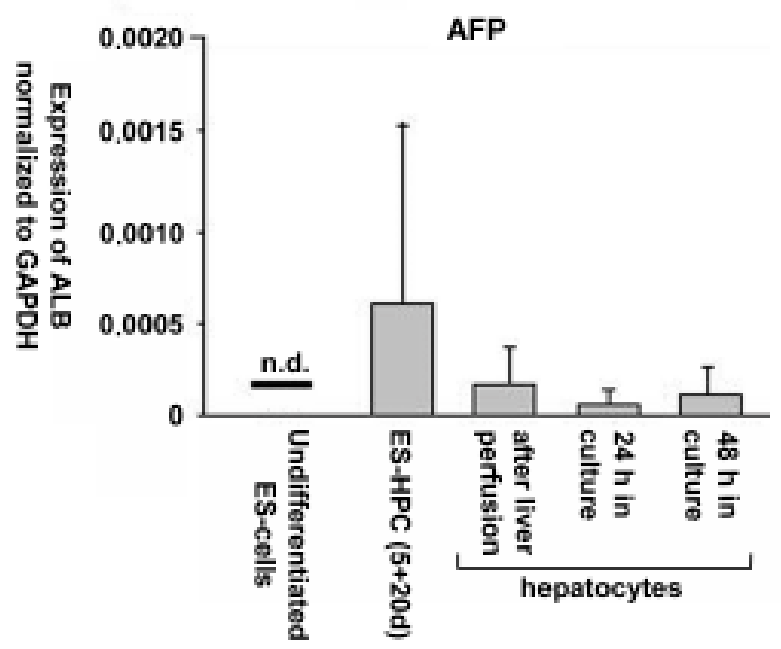

Fig. 4. Expression profiles of $A L B$ and $A F P$ in ES-HPC at different stages of differentiation. Means and standard deviations of relative ALB/ GAPDH (A) and AFP/GAPDH (B) mRNA expression in undifferentiated ES cells, ES-HPC cells at stage $5+20 d$ and hepatocytes isolated from adult liver and after cultivation for 24 and $48 \mathrm{~h}$.

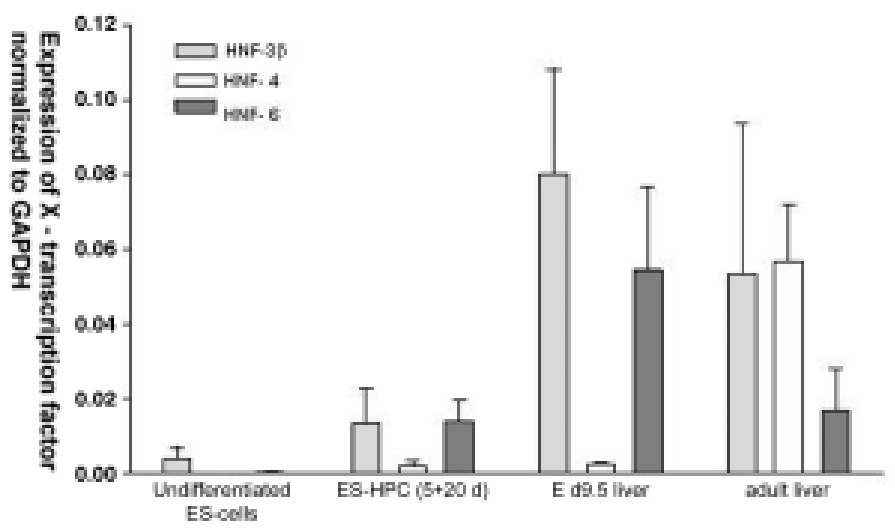

Fig. 5. Expression profiles of transcription factors in ES-HPC at different stages of differentiation. Expression profiles of the transcription factors HNF-3 $\beta$, HNF- $4 \alpha$ and HNF-6 of undifferentiated ES cells, ESHPC cells at stage $5+20 d$ and in fetal and adult liver tissue.
$H N F-4 \alpha$ and $H N F-6$ in various ES-derived cell samples. The level of expression varied throughout the differentiation period, but overall reached the expression rates of primary cultured hepatocytes.

\section{Discussion}

The lack of an accessible adult liver stem cell compartment has fostered studies of hepatocyte differentiation during embryonic and fetal development (Jochheim et al., 2003). Analysis of embryonic and fetal gene expression patterns has become particularly important with the recent development of cell culture protocols that generate cells of hepatic phenotypes from pluripotent ES cells (Chinzei et al., 2002). At the molecular level the induction of embryonic liver development is characterized by the expression of an array of TF. These so called "liver- enriched" TF have their own specific expression pattern during liver development with a distinct narrow time interval of transcriptional initiation. "Knock out" experiments in mice have generated important data on function, time course and position of TF gene expression, and their putative roles in liver organogenesis have been extensively reviewed (Schrem et al., 2002). Little, however, is known about quantitative levels of expression, and how these expression levels relate to various stages of liver development. Our "real-time" RT-PCR analysis shows a striking similarity concerning the pattern as well as the levels found in the developing liver for $H N F-1 \alpha H N F-3 \alpha$, $H N F-4 \alpha$ and HNF-6 TF. The common profile of these mRNAs is characterized by absence in the embryo at $E \mathrm{~d} 7.5$, when the liver has not yet developed, followed by a strong increase in the liver bud at $E d 9.5$ and $d 11.5$ and finally resulting in a decrease at $E d 13.5$ and a stable to slightly increased expression level in adult liver tissue. The peak levels of expression in liver tissue at $E \mathrm{~d} 9.5$ and $\mathrm{E}$ d11.5 indicate, that these TF actively participate in the differentiation cascades and suggest a role as "early phase" priming factors for organ differentiation.

The profile of expression as well as the narrow time frame of peak expression also implicates a role of these TF during transition of pluripotent ES cells into ES- HPC. The ES-HPC show expression of all the TF identified as being upregulated in the early phase of organogenesis. During the time of hepatic differentiation in culture (d10, d20, d30), however, we observed considerable fluctuation of expression levels. This is not surprising, because hepatic differentiation is still incomplete and most likely generates a mosaique pattern of differentiation levels among the cells with a hepatic phenotype.

Whole-mount in situ hybridization showed HNF-3 $\beta$ expression in mouse embryos between days 6.5 and 9.5 of gestation (Sasaki and Hogan, 1993). Detection by RT-PCR in E d7.5 embryos and continuous expression at all stages of liver development, although at very low levels, are in agreement with the known functions of the $\mathrm{TF}$ in node, notochord, and visceral endoderm development. HNF$3 \beta$ mRNA was present in undifferentiated ES cells at low levels despite strong expression of Oct- 4 mRNA indicating the maintenance of a pluripotent phenotype (Tomioka et al., 2002). Upon hepatic differentiation, $H N F 3 \beta$ mRNA was expressed at levels $\sim 3 x$ higher than the levels observed in pluripotent ES cells. Interestingly, it has recently been shown that ES cells expressing the $H N F$ $3 \beta$ gene as a transgene, predominantly differentiate into cells with a hepatic phenotype. These observations and our data underline the view that $H N F-3 \beta$, in addition to its known function as a transcriptional 
activator in the adult liver, acts as a competency factor for hepatic specialization during embryogenesis in vivo as well as in ES cells (Ishizaka et al., 2002).

Several groups have shown that $H N F-4 \alpha$ is expressed in cells of the developing hepatic diverticulum from $\mathrm{E}$ d8.75 on, and that the TF plays a pivotal role for liver maturation and differentiation in HNF3 $\beta$ expressing endodermal tissue (Duncan et al., 1994; Taraviras et al., 1994). Quantitative analysis shows a profound induction of expression in $\mathrm{E} d 9.5$ and d11.5 liver tissue. Similar to $H N F-4 \alpha$, TF HNF-6 is also maximally expressed during this early phase of liver development. Considerable expression of both genes was detected in ES-HPC, but not in undifferentiated ES cells, and levels were stable with minor fluctuations throughout the differentiation period. Although the expression levels were measured at three different time points during hepatic differentiation, the individual time of expression initiation could not be determined for $H N F-4 \alpha$ and $H N F-6$ genes. There are, however, some hints from transfection assays that $H N F-4 \alpha$ is regulated by HNF-6, because of its expression slightly later than HNF-6 (Cereghini, 1996).

$C / E B P \alpha$ belongs to a later stage of the transcriptional hierarchy and is associated with maintenance of a quiescent, mature state of adult hepatocytes (Kuo et al., 1990). Expression in the developing tissue increases steadily from day 13.5 on and reaches maximum levels in the adult liver. No transcripts were observed in earlier stages of development. ES-HPC cells did not express $C /$ $E B P \alpha$ thereby indicating a more immature hepatic phenotype. The partially homologous $C / E B P \beta$ gene, although expressed at the highest level in the developing and adult mouse liver among all TF in our study, was not a suitable marker for ES-HPC differentiation, because substantial expression was also present in mouse embryonic feeder cells.

$A F P$ and $A \angle B$ have frequently served as model genes for developmentally regulated gene expression of the hepatic cell

\section{TABLE 1}

\section{PRIMER /TAQMAN PROBE (5` - FAM; 3‘ - TAMRA) SEQUENCES}

\begin{tabular}{|c|c|}
\hline Gene & $5^{\prime}-3^{\prime}$ direction \\
\hline GAPDH & $\begin{array}{l}\text { cctgcaccaccaactgctta (sense) / tcatgagcccttccacaatg (antisense) } \\
\text { TaqMan probe: cctggccaaggtcatccatgacaa }\end{array}$ \\
\hline$A L B$ & $\begin{array}{l}\text { ctcaggtgtcaaccccaa: (sense) / tccacacaaggcagtctc (antisense) } \\
\text { TaqMan probe: cgtggaggctgcaagaaacctagg }\end{array}$ \\
\hline$A F P$ & $\begin{array}{l}\text { acctccaggcaacaacca (sense) / cactcctctcgtggatgtga (antisense) } \\
\text { TaqMan probe: tgagattcagaagctggc }\end{array}$ \\
\hline$H N F-1 \alpha$ & $\begin{array}{l}\text { agggcacacccatgaagac (sense) / tgccctgcgtgggtgaat (antisense) } \\
\text { TaqMan probe: accaggtgtacagagcggcccgct }\end{array}$ \\
\hline$H N F-1 \beta$ & $\begin{array}{l}\text { tcccacctctctcaacacctc (sense) /gaggatctcccgttgctttct (antisense) } \\
\text { TaqMan probe: gcacccccatgaagacccagaagaga }\end{array}$ \\
\hline$H N F-3 \alpha$ & $\begin{array}{l}\text { caccattacgccttcaacca (sense) /ctggcattcatgaagaagttgc (antisense) } \\
\text { TaqMan probe: acaatcaccatctcccagcagctgg }\end{array}$ \\
\hline$H N F-3 \beta$ & $\begin{array}{l}\text { ttgagagtattgaaaggcagtgct (sense) / aatgcatccagaatgtaaggtgaa (antisense) } \\
\text { TaqMan probe: aaccggttatgcacattggagcccttt }\end{array}$ \\
\hline$H N F-4 \alpha$ & $\begin{array}{l}\text { tgccaacctcaattcatcca (sense) / gctcgaggctccgtagtgtt (antisense) } \\
\text { TaqMan probe:acagcctgagcgtcagtgccctgt }\end{array}$ \\
\hline HNF-6 & $\begin{array}{l}\text { gaaaataagcgtccgtccaaag (sense) / ctggcattcatgaagaagttgc (antisense): } \\
\text { TaqMan probe: acaaatcaccatctcccagcagctgg }\end{array}$ \\
\hline$C / E B P \alpha$ & $\begin{array}{l}\text { aagaagtcggtggacaagaacag (sense) / gttgcgttgtttggctttatctc (antisense) } \\
\text { TaqMan probe: gtacggcgggaacgcaacaacatc }\end{array}$ \\
\hline$C / E B P \beta$ & $\begin{array}{l}\text { ggaaataagcgtccgtccaaag (sense) / acaaaaccaaaaacatcaacaacc (antisense) } \\
\text { TaqMan probe: agccgggccctgagtaatcacctt }\end{array}$ \\
\hline
\end{tabular}

lineage (Derman et al., 1981; Panduro et al., 1987). While AFP mRNA concentrations drop from abundant levels in fetal liver to very low levels in the adult organ, $A \angle B$ mRNA concentrations increase gradually from early fetal to adult liver. ES-HPC cell cultures consistently expressed $A F P$ and $A \angle B$ mRNA in our experiments. Additionally, immunofluorescence images showed ALB and AFP protein expression in about $20 \%$ of Hoechst 33342 labelled cells. However, $A \angle B$ expression levels in ES-HPC were several orders of magnitude lower compared to adult liver and primary hepatocytes and were in the range of levels observed for E d10.5-11.5 fetal liver tissue. Since gene expression levels observed in primary tissue may be down regulated during cultivation, we additionally analyzed expression of our candidate genes in cultured adult hepatocytes. Compared to the primary tissue, in cultured hepatocytes we found reduced gene expression levels which, however, still exceeded those of ES-HPC by several orders of magnitude.

The method of quantitative gene expression profiling by "real time" RT-PCR as applied in our study is limited by the fact, that both the analyzed tissue and ES-derived populations consist of more than one cell compartment. During fetal development, the liver is the site of hematopoiesis and the number of non-hepatocytes varies over time (Sonoda et al., 2001). In particular, the analysis of the $\mathrm{E} d 13.5$ liver tissue may have been confounded by the presence of blood forming cells. In a previous study, microarray analysis of fetal liver showed extensive expression of genes known to be involved in hematopoiesis (Jochheim et al., 2003) and studies are underway to combine laser microdissection techniques and linear amplification of $\mathrm{mRNA}$ with quantitative RTPCR to increase the specificity of the results (Cantz et al., 2003).

Our gene expression profiling of murine liver development indicates that ES-HPC express many of the "early phase" TF (in the range of levels observed for E d10.5-11.5 fetal liver tissue), which are known to be involved in hepatic specification. The lack of "late phase" TF such as CEBP $\alpha$ and low levels of $A L B$ and $A F P$ expression, however, point to an immature hepatic phenotype of the ES-HPC. The ES-HPC maturation state may have important consequences, when experimental or therapeutic applications are considered, since immature ES-HPC may lack the necessary metabolic competence in extracorporal liver assist devices, cell transplantation or drug toxicity studies. Transgene expression of liver specific genes and histotypic culture similarly as recently shown for pancreatic differentiation (Blyszczuk et al., 2003) and/ or technologies to separate ES-HPC have to be applied to improve the differentiation and maturation status of hepatic cells.

\section{Materials and Methods}

\section{Staging and preparation of embryos}

Mouse embryos (all extra-embryonic parts of the embryo were removed) at various stages of gestation as well as liver tissue of 8 weeks old adult mice were obtained by mating random-bred BALB/C animals. At noon of the day of vaginal plug appearance was considered to be embryonic day 0.5 .

\section{RNA preparation and characterization}

RNA was prepared using the Qiagen RNeasy Mini Kit (Qiagen, Hilden, Germany) according to standard protocols. Residual chromosomal DNA was digested with DNase I (Life Technologies, Karlsruhe, Germany). The Agilent 2100 Bioanalyzer and the RNA 6000 LabChip kit (Agilent Technologies, Waldbronn, Germany) were used to determine the concentration and 
purity/integrity of the RNA samples. Chips were prepared according to the protocol of the manufacturer: 12 samples ( $1 \mu \mathrm{l}$ each) (concentrations ranging from $25-250 \mathrm{ng} / \mu \mathrm{l}$ ) were loaded into sample wells of the chip.

\section{Synthesis of cDNA}

First strand cDNA was synthesized from $5 \mu \mathrm{g}$ of total RNA in a $20 \mu \mathrm{l}$ reaction using an oligo(dT) primer (Unip 2). One $\mu$ l of the primer was mixed with $5 \mu \mathrm{g}$ of total RNA or $1 \mu \mathrm{g}$ PolyA ${ }^{(+)}$- RNA, and sterile double distilled water was added to a total volume of $12 \mu \mathrm{l}$. The mixture was incubated at $70^{\circ} \mathrm{C}$ for $10 \mathrm{~min}$ and quickly chilled on ice. After a centrifugation step $4 \mu \mathrm{l}$ of $5 \mathrm{x}$ first strand buffer, $2 \mu \mathrm{l}$ of $0.1 \mathrm{M}$ DTT and $1 \mu \mathrm{l}$ of $10 \mathrm{mM}$ dNTP - mix were added. The contents were gently mixed and incubated at $42^{\circ} \mathrm{C}$ for 2 min. $1 \mu \mathrm{l}$ of the enzyme Superscript ${ }^{\mathrm{TM}}$ II (Life Technologies, Karlsruhe, Germany) was added. The reaction was continued for $50 \mathrm{~min}$ at $42^{\circ} \mathrm{C}$, followed by heating the solution at $70^{\circ} \mathrm{C}$ for $15 \mathrm{~min}$ for inactivation.

\section{Oligonucleotide and TaqMan probe design}

Primer sequences and TaqMan probes for "real-time" RT-PCR were designed using the primer design software "Primer3" of the Whitehead Institute for Biomedical Research, Boston, and purchased from suppliers (MWG Biotech, Ebersberg, Germany and PE Applied Biosystems, Weiterstadt, Germany). Primer and TaqMan probe sequences are shown in Table 1.

\section{"Real - time" RT - PCR analysis}

RNA expression normalized to the house keeping gene GAPDH was measured by "real-time" RT - PCR with the iCycler System (BIO-RAD, München, Germany) using the iCycler iQ Real-Time Detection System Software (Version 2.1). Optimal reaction conditions were 40 cycles of a twophase PCR (denaturation at $95^{\circ} \mathrm{C}$ for $15 \mathrm{~s}$; annealing at $55^{\circ} \mathrm{C}$ for $30 \mathrm{~s}$ ) after an initial denaturation step ( $95^{\circ} \mathrm{C}$ for $10 \mathrm{~min}$ ).

The TaqMan probes were labelled with a fluorescent reporter dye (6carboxy-fluorescein [FAM]) at the 5' end and a fluorescent quencher dye (6carboxy-tetramethyl-rhodamine [TAMRA]) at the 3' end. Using the "Standard Curve Method" as described in the User Bulletin \#2; ABI PRISM 7700 Detection System,the target gene expression was determined for each stage of 3-5 individual samples and from each cDNA sample at least 3 PCR - reactions were performed from both the target gene and the internal reference gene (GAPDH) to normalize for differences in individual sample concentration and experimental handling. The amount of target and endogenous reference concentrations were then determined from the appropriate standard curve and the unit from the standard curve drops out. The amount of the target mRNA was divided by the amount of GAPDHmRNA for normalization of target values under recognition of the dilution factor, e.g., iCycler experiments were run with cDNA, equivalent to $20 \mathrm{ng}$ whole RNA for the measurement of transcription factors and only $0.5 \mathrm{ng}$ were needed to obtain reasonable $\mathrm{C}_{\mathrm{t}}$-values for $A F P$ and $A L B$.

\section{Standard curves}

For demonstrating linearity of the assay system a standard curve for each target gene was calculated from serial dilutions of the cDNA template by plotting the log value of the starting concentration versus the threshold cycle $\left(\mathrm{C}_{t}\right)$. The amount of the target and the internal reference gene GAPDH in each tissue sample were calculated from standard curves using cDNA dilutions from a single lot of pooled mouse embryonic liver CDNA ( $E$ d13.5, Quantum Appligene, Heidelberg, Germany, ECDLI 135, Lot: FA3-1a ) or from liver cDNA of adult mice (Ambion Inc., Austin, Texas). The dilutions used for creating the standard curves included at least 4 data points spanning 4-5 orders of magnitude with a correlation coefficient $(r)>0.9$ for all experiments and genes.

\section{Sequencing of RT-PCR products}

PCR-products of the I-Cycler runs were used for ligation into the pGEM$T$ vector (Promega). Colonies were grown overnight on microtiter plates and an aliquot was processed further as a template in a "sequencing" - PCR
( $30 \mathrm{~s}$ at $96^{\circ} \mathrm{C}, 5 \mathrm{~s}$ at $50^{\circ} \mathrm{C}, 60 \mathrm{~s}$ at $60^{\circ} \mathrm{C}$ ) using vector-specific primers from the manufacturer (Promega). Sequencing was done with the ABI 3700 Genetic Analyzer (PE Applied Biosystems) following the instructions of the manufacturer. The sequences were analyzed with the NCBI Program Blast Search (WWW.NCBI.NLM.NIH.GOV/Blast).

\section{Culture of undifferentiated ES cells and differentiation into ES-HPC}

ES cells of line R1 were cultivated on a feeder layer of primary mouse embryonic fibroblasts in the presence of recombinant human leukemia inhibitory factor (LIF) as described (Nagy et al., 1993; Wobus et al., 2002). For hepatic differentiation, ES cells $(n=600)$ were used to form embryoid bodies (EBs) that were cultivated in hanging drops as described elsewhere. At day 5, EBs were plated onto collagen type l-coated plates in Hepatocyte Culture Medium (Clonetics, Bio-Whittaker; A Cambrex Company; Belgium) supplemented with $20 \%$ FCS (Gibco BRL, Life Technologies, Eggenstein, Germany) and penicillin-streptomycin (Gibco, stock solution diluted 1:100) (Kania et al., 2003). The cells were cultivated until day 5+30. Samples for "real-time" RT-PCR and immunofluorescence analyzes were collected at stages $5+10 d, 5+20 d, 5+30 d$.

\section{Immunofluorescence analysis}

For immunofluorescence, ES-HPC at stage $5+20 \mathrm{~d}$ were fixed with methanol: aceton (7:3) at $-20^{\circ} \mathrm{C}$ for $10 \mathrm{~min}$. Bovine serum Albumin

(1\% in PBS) was used to inhibit unspecific labelling (30 min at room temperature). The following primary antibodies were used: goat anti--fetoprotein (1:100; Santa Cruz Biotechnol., USA), Albumin (1: 100; Serotec, USA). Cy ${ }^{3 T M}$-conjugated donkey anti-goat IgG and FITC-conjugated donkey anti-sheep IgG (both from Jackson ImmunoResearch Laboratories, PA) were used as secondary antibodies. To label the nuclei for a semi-quantitative estimation of immunofluorescence signals, cells were incubated in $5 \mu \mathrm{g} /$ $\mathrm{ml} \mathrm{Hoechst} 33342$ in PBS at $37^{\circ} \mathrm{C}$ for 10 min. After washing in PBS $(3 \mathrm{x})$ and in aqua dest. (1x), the specimens were embedded in mounting medium (Vectashield, Vector Laboratories Inc., Burlingame, CA, USA).

Labelled cells were analyzed by the confocal laser scanning microscope (CLSM) LSM-410 (Carl Zeiss, Jena, Germany) using the following excitation lines/barrier filters: $364 \mathrm{~nm} / 450-490 \mathrm{BP}$ (Hoechst 33342), 488 nm/510-525BP (FITC/DTAF), 543 nm/570LP (Cy3).

\section{Determination of percentage values of Hoechst-labelled cells}

Cells were analyzed for immunofluorescence signals and the percentage number of immunopositive cells relative to a total number of $(n=1000)$ Hoechst 33342-labelled cells is given.

\section{Liver perfusion and hepatocyte cell culture}

Hepatocytes were isolated from livers of BALB/C mice by a standard two-step collagenase perfusion (Seglen, 1979$)$. Viability $(75 \%+/-6 \%)$ was estimated by trypan blue dye exclusion. Hepatocytes were plated at a density of $5 \times 10^{5}$ viable cells on collagen-coated cell culture dishes with a diameter of $35 \mathrm{~mm}$ in $2 \mathrm{ml}$ culture medium supplemented with $10 \% \mathrm{FCS}$ and incubated at $37^{\circ} \mathrm{C}$ in a humidified atmosphere composed of $95 \%$ air and $5 \%$ $\mathrm{CO}_{2}$. RNA was prepared from hepatocytes after $24 \mathrm{~h}$ and $48 \mathrm{~h}$ in culture and analyzed for expression of $A L B, A F P, H N F-3 \beta, H N F-4 \alpha$ and $H N F-6$ by quantitative RT-PCR.

\section{Statistical analysis}

Data are presented as means \pm SD. Statistical analysis was performed with the Sigma Stat Software (Sigma, St. Louis, U.S.A). The paired Student's $t$ - test was used for all data. A p value $<0.05$ was considered to be significant.

\section{Acknowledgements}

The authors want to thank $R$. Mörstedt for expert assistance in mice breeding and animal care and Tobias Cantz for expert help in liver preparation. This work was supported by a grant from the Deutsche Forschungsgemeinschaft (KFO 110/1). 


\section{References}

BLYSZCZUK, P., CZYZ, J., KANIA, G., WAGNER, M,. ROLL, U., ST-ONGE, L. and WOBUS, A. M. (2003). Expression of Pax4 in embryonic stem cells promotes differentiation of nestin-positive progenitor and insulin-producing cells. Proc. Natl. Acad. Sci. USA. 100: 998-1003.

CANTZ, T., JOCHHEIM, A., CIESLAK, A., HILLEMANN, T., SCHARF, J., MANNS, M.P. and OTT, M. (2003). PCR-based quantification of amplified RNA from laser microdissected mouse liver samples. Experimental and Molecular Pathology 75: 53-57.

CANTZ, T., ZUCKERMAN, D.M., BURDA, M.R., DANDRI, M., GÖRICKE, B., THALHAMMER, S., HECKL, W.M., MANNS, M.P., PETERSEN, J. and OTT, M. (2003). Quantitative Gene Expression Analysis Reveals Transition of Fetal Liver Progenitor Cells to Mature Hepatocytes after Transplantation in uPA/RAG-2 Mice. Am. J. Pathol. 162:37-45.

CEREGHINI, S. (1996). Liver-enriched transcription factors and hepatocyte differentiation. FASEB J. 10(2): 267-82.

CHINZEI, R., TANAKA, Y., SHIMIZU-SAITO, K., HARA, Y., KAKINUMA, S., WATANABE, M., TERAMOTO, K., ARII, S., TAKASE, K., SATO, C., TERADA, N. and TERAOKA, $H$. (2002). Embryoid-body cells derived from mouse embryonic stem cell line show differentiation into functional hepatocytes. Hepatology 36(1): 22-9.

DERMAN, E., KRAUTER, K., WALLING, L., WEINBERGER, C., RAY, M. and DARNELL, J.E. (1981). Transcriptional control in the production of liver-specific mRNAs. Cel/23: 731-739.

DUNCAN, S.A., MANOVA, K., CHEN, W.S., HOODLESS, P., WEINSTEIN, D.C., BACHVAROVA, R.F. and DARNELL, J.E. Jr. (1994). Expression of transcription factor HNF-4 in the extraembryonic endoderm, gut, and nephrogenic tissue of the developing mouse embryo: HNF-4 is a marker for primary endoderm in the implanting blastocyst. Proc. Natl. Acad. Sci. USA. 2;91(16): 7598-602.

GUPTA, S. (2002). Hepatocyte transplantation. J Gastroenterol Hepato/3: 287-293.

HAMAZAKI, T., IIBOSHI, Y., OKA, M., PAPST, P.J., MEACHAM, A.M., ZON, L.I. and TERADA N. (2001). Hepatic maturation in differentiating embryonic stem cells in vitro. FEBS Lett. 497: 15-19.

ISHIZAKA, S., SHIROI, A., KANDA, S., YOSHIKAWA, M., TSUJINOUE, H., KURIYAMA, S., HASUMA, T., NAKATANI, K. and TAKAHASHI, K. (2002). Development of hepatocytes from ES cells after transfection with the HNF-3beta gene. FASEB J. 16(11): 1444-6.

JOCHHEIM, A., CIESLAK, A., HILLEMANN, T., CANTZ, T., SCHARF, J., MANNS, M.P. and OTT, M. (2003). Multi-stage analysis of differential gene expression in $\mathrm{B} A \angle B / \mathrm{C}$ mouse liver development by high-density microarrays. Differentiation71: 62-72.

JONES, E.A., CLEMENT-JONES, M., JAMES, O.F. and WILSON, D.I. (2001). Differences between human and mouse alpha-fetoprotein expression during early development. J. Anat. 198(Pt 5): 555-9.

JONES, E.A., TOSH, D., WILSON, D.I., LINDSAY, S. and FORRESTER, L.M. (2002). Hepatic differentiation of murine embryonic stem cells. Exp. Cell Res. 272(1): 15-22.

KAMIYA, A., KINOSHITA, T., ITO, Y., MATSU,I T., MORIKAWA, Y., SENBA, E., NAKASHIMA, K., TAGA, T., YOSHIDA, K., KISHIMOTO, T. and MIYAJIMA, A. (1999). Fetal liver development requires a paracrine action of oncostatin $M$ through the gp 130 signal transducer. EMBO. J. 18(8): 2127-36.

KANIA, G., BLYSZCZUK, P., CZYZ, J., NAVARRETE-SANTOS, A. and WOBUS A.M. (2003). Differentiation of mouse embryonic stem cells into pancreatic and hepatic cells. Methods in Enz. 365: 287-303.
KUO, C.F., XANTHOPOULOS, K.G. and DARNELL, J.E. Jr. (1990). Fetal and adult localization of $C / E B P$. evidence for combinatorial action of transcription factors in cell-specific gene expression. Development 109(2): 473-81.

LAZAREVICH, N.L. (2000). Molecular mechanism of alpha-fetoprotein gene expression. Biochemistry 65(1): 117-33.

MIYASHITA, H., SUZUKI, A., FUKUO, K., NAKAUCHI, $\mathrm{H}$. and TANIGUCHI, $\mathrm{H}$. (2002). Evidence for hepatocyte differentiation from embryonic stem cells in vitro. Cell Transplant 11(5): 429-34.

NACER-CHERIF, H., BOIS-JOYEUX, B., ROUSSEAU, G.G., LEMAIGRE, F.P. and DANAN, J.L. (2003). Hepatocyte nuclear factor- 6 stimulates transcription of the alpha-fetoprotein gene and synergizes with the retinoic-acid-receptor-related orphan receptor alpha-4. Biochem. J. 369(Pt3): 583-91.

NAGY, A., ROSSANT, J., NAGY, R., ABRAMOW-NEWERLY, W. and RODER, J.C. (1993). Derivation of completely cell culture-derived mice from early passage embryonic stem cells. Proc. Natl. Acad. Sci. USA. 90: 8424-8428.

PANDURO, A., SHALABY, F. and SHAFRITZ, D.A. (1987). Liver-specific gene expression in various pathophysiologic states. Hepatology 7(1): 10-18.

SASAKI, H. and HOGAN, B.M.L. (1993). Differential expression of multiple fork head related genes during gastrulation and axial pattern formation in the mouse embryo. Development 118: 47-59.

SCHREM, H., KLEMPNAUER, J. and BORLAK, J. (2002). Liver-enriched transcription factors in liver function and development. Part I: the hepatocyte nuclear factor network and liver-specific gene expression. Pharmacol. Rev. 54(1): 129-58.

SEGLEN, P.O. (1979). Hepatocyte suspensions and cultures as tools in experimental carcinogenesis. J. Toxicol. Environ. Health 5(2-3): 551-60.

SONODA, Y., SASAKI, K., SUDA, M. and ITANO, C. (2001). Ultrastructural studies of hepatoblast junctions and liver hematopoiesis of the mouse embryo. Kaibogaku Zasshi76(5): 473:82.

TARAVIRAS, S., MONAGHAN, A.P., SCHUTZ, G. and KELSEY, G. (1994). Characterization of the mouse HNF-4 gene and its expression during mouse embryogenesis. Mech. Dev. 48(2): 67-79.

TIRONA, R.G., LEE, W, LEAKE B.F., LAN, L.B., CLINE, C.B., LAMBA, V., PARVIZ, F., DUNCAN, S.A., INOUE, Y., GONZALEZ, F.J., SCHUETZ, E.G. and KIM, R.B. (2003). The orphan nuclear receptor HNF4alpha determines PXR- and CARmediated xenobiotic induction of CYP3A4. Nat. Med. 9(2):220-4.

TOMIOKA, M., NISHIMOTO, M., MIYAGI, S., KATAYANAGI, T., FUKUI, N., NIWA, H., MURAMATSU, M. and OKUDA, A. (2002). Identification of SOX-2 regulatory region which is under the control of Oct-3/4-Sox-2 complex. Nucleic. Acids. Res. 30(14): 3202-13

WOBUS, A.M., GUAN, K., YANG, H.-T. and BOHELER K. (2002). Embryonic stem cells as a model to study cardiac, skeletal muscle, and vascular smooth muscle cell differentiation. Methods Mol. Biol. 185: 127-56.

ZHANG, Y., BAI, X.F. and HUANG, C.X. (2003). Hepatic stem cells : existence and origin. World J Gastroentero/9(2):201-204

Received: August 2003

Reviewed by Referees: September 2003

Modified by Authors and Accepted for Publication: October 2003 